УДК 541.64

DOI: $10.33184 /$ bulletin-bsu-2020.4.14

\title{
INFLUENCE OF THE NATURE OF DRUGS ON THE CONFORMATIONAL AND SUPRAMOLECULAR STATES OF SOME POLYMERS USED AS PROLONGATORS OF THE EFFECT OF DRUGS
}

(C) A. S. Shurshina*, A. R. Galina, M. Yu. Lazdina,

\author{
A. S. Titlova, E. I. Kulish
}

Bashkir State University

32 Zaki Validi Street, 450076 Ufa, Republic of Bashkortostan, Russia.

*Email: onlyalena@mail.ru

\begin{abstract}
The work is devoted to the creation of dosage forms of prolonged action, based on physiologically active polymers - nonionic polyvinyl alcohol and ionic chitosan and sodium salt of succinyl chitosan. Low molecular weight electrolytes cefazolin, lidocaine, and non-electrolyte dioxidine were used as drugs. It was found that in the case of the use of ionic polymers and drugs, which are low molecular weight electrolytes, their addition to polymer solutions in a wide concentration range is accompanied by changes in the conformational and supramolecular state of polymers, which can not affect the interaction of polymers with drugs, and, consequently, and on the ability of polymers to prolong drug release.
\end{abstract}

Keywords: polyelectrolytes, rheology, conformational-supramolecular state.

\section{Introduction}

Today the creation of long-acting dosage forms is impossible to imagine without the usage of polymers [1-8]. Even with the simple mixing the level of prolongation of drug release can be achieved due to/ thanks to the fact that macromolecules have a higher (level) of viscosity than lower molecular weight ones.

Frequently, the polymers with their own physiological activity are used as prolongators [9-13]. In this case, macromolecules have an effect on organism even if no low molecular weight pharmacological substances are introduced into their structure. Under such conditions macromolecules perform both main and side functions and act as drug carriers and as biologically active compounds.

In most cases, physiologically active macromolecules are polyelectrolytes, i.e. polymers carrying a charge on their chain. The usage of polyelectrolytes as a basis of polymer dosage forms is complex because the behavior of water polyelectrolyte solutions with electrostatic interactions is different from the behavior of nonionic ones [14]. For example, the conformational state of polyelectrolytes, besides to temperature, the chemical nature of the polymer and the solvent, is largely determined by such factors as the degree of counterions binding by macroions, the chemical nature, and the concentration of low-molecular-weight salts. Due to the fact that medicinal substances frequently are low-molecular electrolytes, the aim of this work is the study of peculiarities of the influence of certain medicinal substances, both of electrolyte and non-electrolyte nature, on the conformational and supramolecular state of polymers. Two substances were used as physiological active polymers of the polyelectrolyte nature: chitosan that was chosen as a polycation, and chitosan succinate sodium salt that plays the role of polyanion. Polyvinyl alcohol was used as a physiologically active non-polyelectrolyte polymer. Sodium salt of cefazolin (electrolyte), lidocaine hydrochloride (electrolyte), and dioxidine (non-electrolyte) were used as medicinal substances.

\section{Experimental}

The sample of chitosan (CTS) with the molecular weight of $113000 \mathrm{amu}$, sodium salt of chitosan succinyl (SCHTZ) with the molecular weight of 67000 and polyvinyl alcohol (PVA) with the molecular weight of 45600 were taken for the research. The degree of substitution of the SCHTZ samples for amino groups was $75 \%$. The degree of deacetylation of the initial CTS samples, from which the CTS samples were obtained, is $82 \%$.

Lidocaine, cefazolin and dioxidine were used as drugs.

$1 \%$ acetic acid in the case of CTS and distilled water in the case of SCHTZ and PVA were used as solvents. Polymer solutions were prepared by stirring on a magnetic stirrer for 24 hours at room temperature.

Intrinsic viscosity of the dilute polymer solutions was defined using a Ubbelode viscometer at the temperature of 25 degrees with an error of one degree. According to Baranov's approach [15], the definition

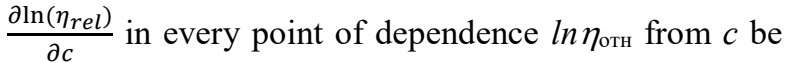
considered as "the current value of intrinsic viscosity":

$$
[\eta]^{*}=\frac{\partial \ln \left(\eta_{r e l}\right)}{\partial c}
$$

where $\eta_{\text {отн }}-$ is the value of the relative viscosity of the polymer solution, $\mathrm{c}$ is the polymer concentration in the solution.

It is obvious that $\mathrm{c} \rightarrow 0$ the value of $[\eta]^{*}$ corresponds to the slop of the dependence $\ln \eta_{\text {rel }}$ from $c$ and coincides with the value of the intrinsic viscosity $[\eta]$ that describes the behavior of the isolate macromolecules.

To define the flow of aggregation processes we use the approach that was described in this work [16]. 
Rheological measurements were carried out on a Haake Mars III modular dynamic rheometer at $20{ }^{\circ} \mathrm{C}$ in the oscillatory mode in the linear viscoelastic region (at the oscillation frequency from 0.1 to 10 Hertz) using a cone-plane measuring geometry.

\section{Results and discussion}

It is known that polymers in solutions can exists in different concentration modes [17-19]. In the mode of diluted solutions with the concentration of $\mathrm{C}$ that is less than the concentration of crossover $C^{*}=1 /[\eta]$, where $[\eta]-$ is the intrinsic viscosity, macromolecules are isolated from each other and do not interact with each other while the viscosity of the polymer solution increases with increasing the concentration according to the linear law $\eta \sim C^{\delta}$, where $\delta=1.00$.

In this area of concentrations the solutions of nonpolyelectrolyte PVA behaves like a Newtonian fluid from a rheological point of view, and its viscosity does not depend on the shear rate or the oscillation frequency (fig. 1). The increase in the concentration of PVA in solution is accompanied by a regular decrease in the size of the macromolecular coil (values of the "current" intrinsic viscosity) (fig. 2a) and the increase in the degree of aggregation of the macromolecules (fig. 2b).

\section{a)}

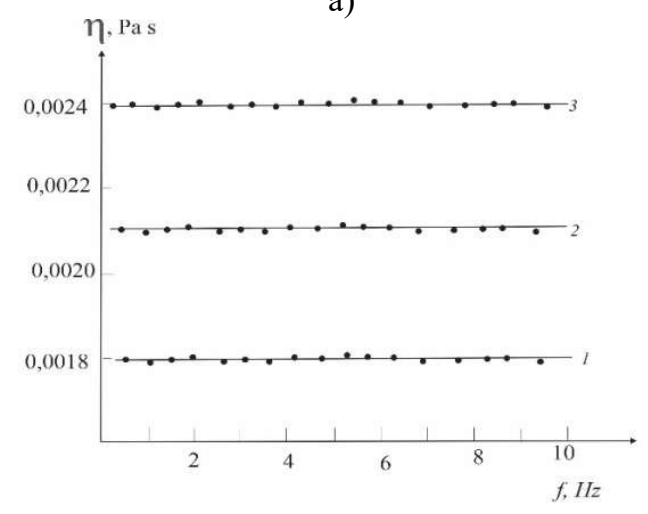

With the concentration of $C$, that is large that the concentration of $C^{*}$, macromolecules start to interact with each other (aggregate) and viscosity begin to be dependence on the concentration according to the power law $\eta \sim C^{\delta}$, where $\delta>1$. Moreover, on going to the area of semi-dilute solutions, the nature of dependence of viscosity on shear rate changes, the viscosity starts to decrease with the increase in shear rate (or the oscillation frequency), i.e. the PVA solution behaves as like a pseudo plastic liquid (fig. 1 b.).

The increase in the concentration of the polymer in solutions results not only in the increase in the aggregation of macromolecules, but also in the formation of networks entanglements at the $\mathrm{C}_{\mathrm{e}}$ concentration which is easy to determine from the onset of a sharp increase of viscosity.

On fig. 3 three areas clearly stand out. The first one is the area of semi-dilute solutions in which macromolecules do not interact with each other. The second one is the area of concentrated solutions with a fully formed fluctuation network of meshes of macromolecules. In this area viscosity increases with the increase of concentrate according to the power law $\eta \sim C^{n}$, where $n \approx 5$. The last one is the intermediate area of semi-diluted solutions, which is characterized by an intense rearrangement of the supramolecular structure and the formation of a network of meshes [20].

b)

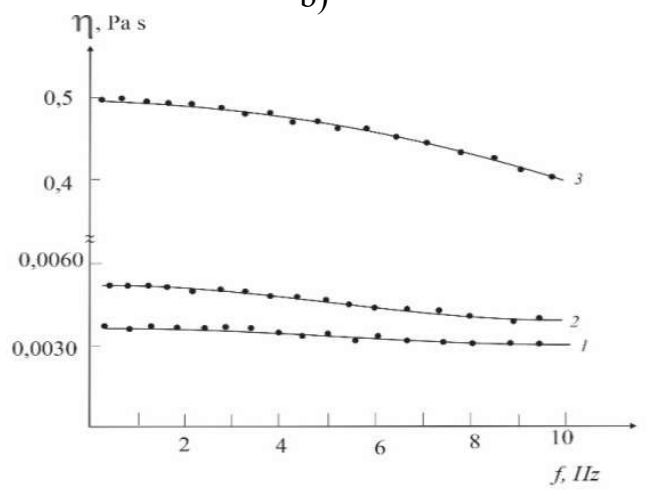

Fig. 1. The dependence of viscosity on oscillation frequency for PVA solutions with concentrations of 0.1 (1a), 0.2 (2a) and 0.3 (3a) g/dl and 1.0 (1б), 3.0 (2б) и 10.0 (3б) g/dl.

a)

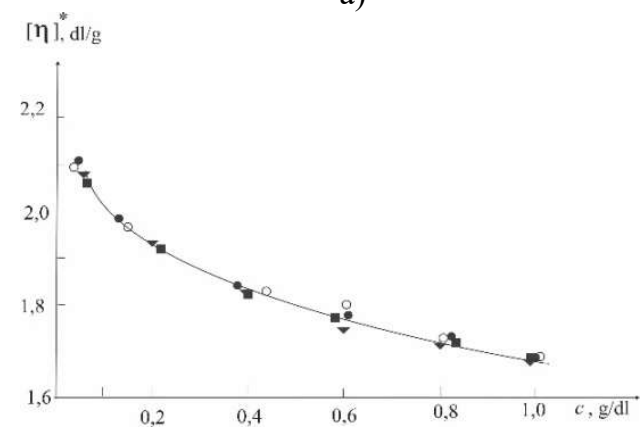

b)

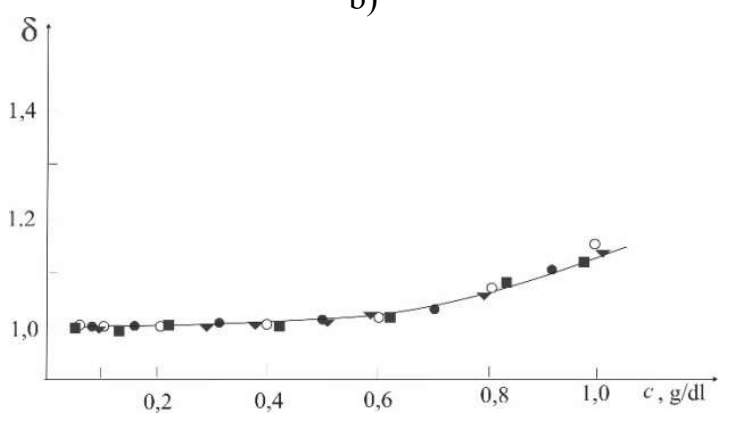

Fig. 2. The dependence of value of the current intrinsic viscosity (a) and the degree of aggregation(b) on the concentration of PVA in the absence and presence of the drug and DO, CFZ and LD, taken at the concentration of $0.1 \mathrm{~mol} / \mathrm{mol} \mathrm{CTS}$. 


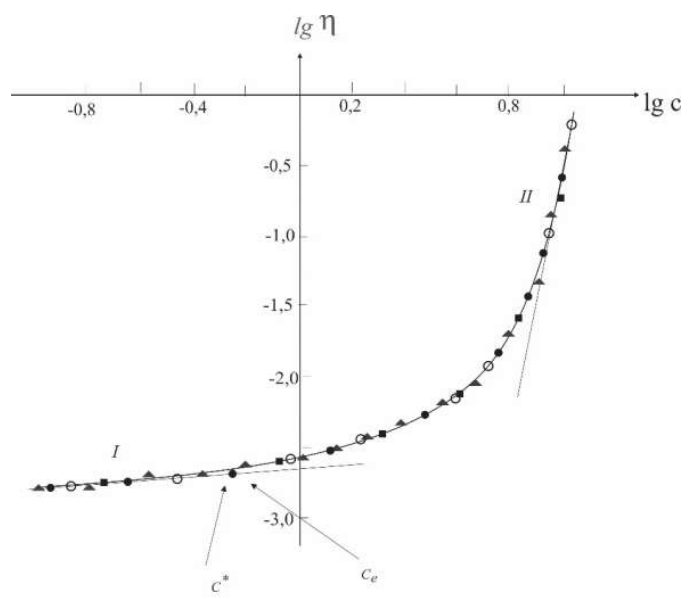

Fig. 3. The dependence of complex viscosity of PVA solutions on the concentration of polymer in the solution in logarithmic coordinates in the absence and in the presence of DO (•), LD ( $),$ CFZ ( $)$, taken at a concentration of $0.1 \mathrm{~mol} / \mathrm{l}$.

a)

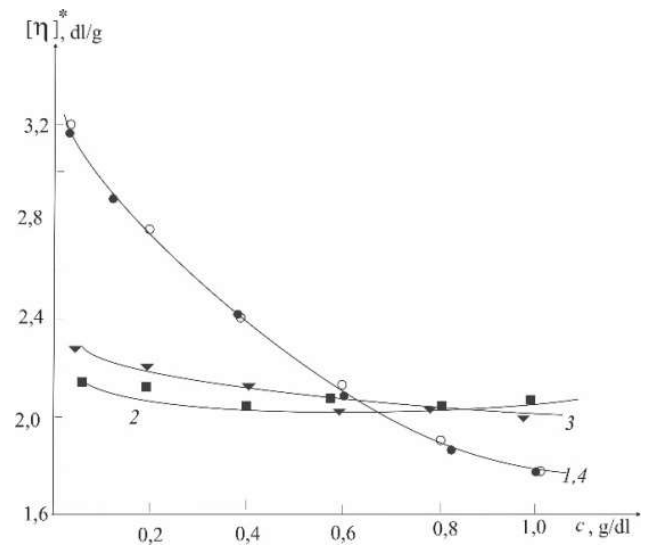

b)

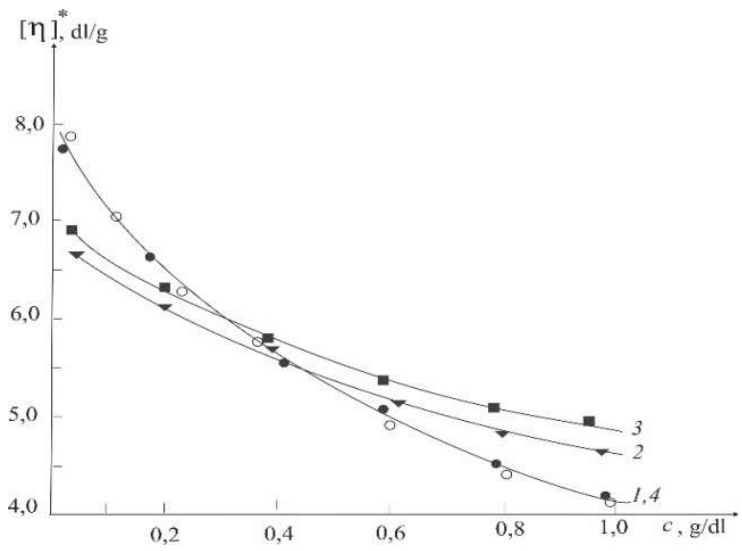

Fig. 4. The dependence of "current" intrinsic viscosity on SCHTZ (a) and CTS (b) in the absence (1) and presence (2-4) of drug LD (2), CFZ (3) and DO (4) taken at the concentration of $0.1 \mathrm{~mol} / \mathrm{mol} \mathrm{SCHTZ.}$

a)

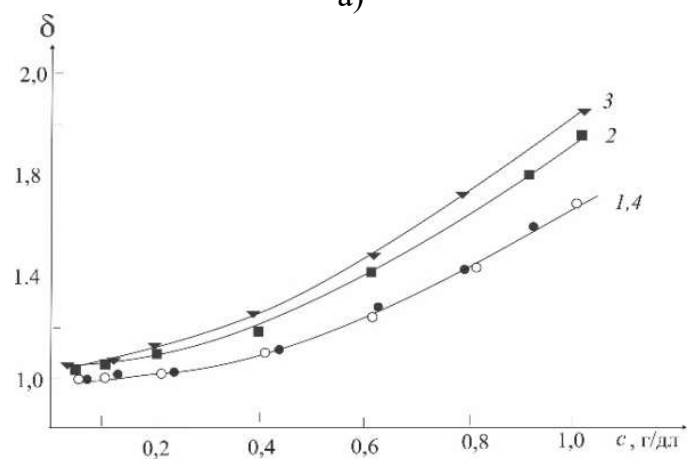

b)

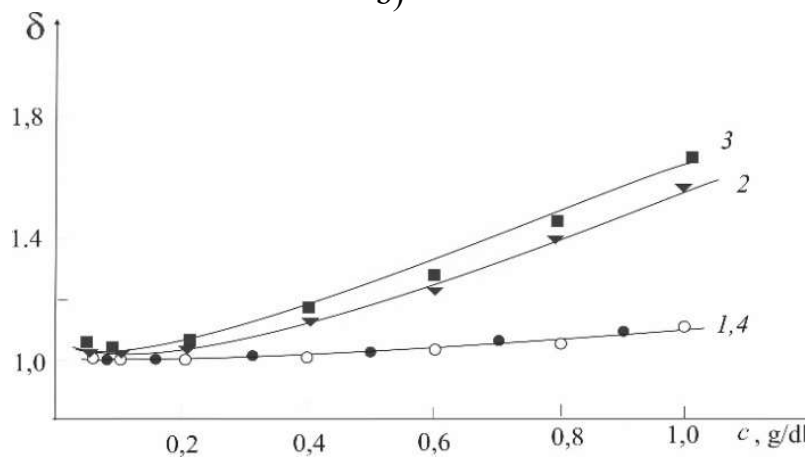

Fig. 5. The dependence of the degree of aggregation on the concentration of SCHTZ (a) and CTS (b) in solution in the absence (1) and presence (2-4) of the medicinal substance CFZ (2), LD (3) and DO (4).

The sharp increase in viscosity is due to the fact that on going from dilute solutions to semi-dilute solutions the mechanism of mass transfer changes (from translational to reptational) and this changes are associated with the formation of a fluctuation network of meshes [21-22].

The increase in the concentration of ionic SCHTZ and CTS in solutions is also accompanied by the decrease in intrinsic viscosity (curve 1, fig. 4) and the 
decrease in the degree of aggregation of macromolecules (curve 1, fig. 5). However, the rheological behavior of polyelectrolytes has its own peculiarities.

For example, in the solutions of non-ionic polymers the fluctuation network of meshes is formed almost immediately after reaching the crossover point. Accordingly, the $\mathrm{C} *$ value coincides with the $\mathrm{C}_{\mathrm{e}}$ value (fig. 3). However, in the solutions of ionic polymers there is an electrostatic repulsion of like-charged chains which prevents the coils from penetrating into each other and the formation of a network of meshes. According to it, in the solutions of polyelectrolytes

a)

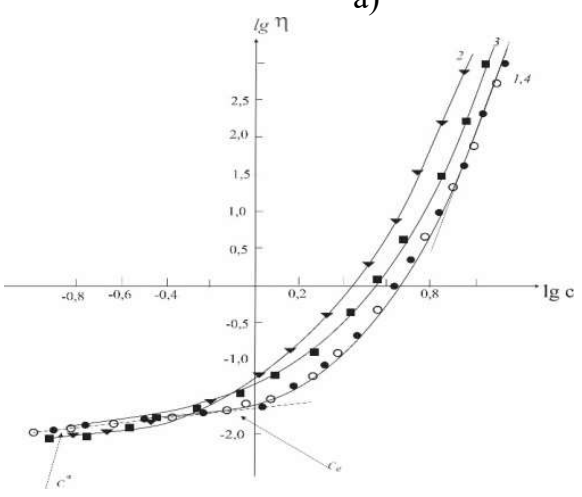

there is the area of semi-dilute solutions in which the coils interact with each other, but still do not create the network of meshes. This feature of the behavior of polyelectrolytes is indicated by both theoretical calculations and a few experimental works in this area [23-25].

Indeed, unlike PVA solutions, a sharp increase in the dynamic viscosity of CTS and SCHTZ solutions and the transition from one concentration regime (diluted solution) to another (semi-diluted) occurs not at a crossover concentration $C^{*}=1 /[\eta]$, but somewhat later (fig. .6).

b)

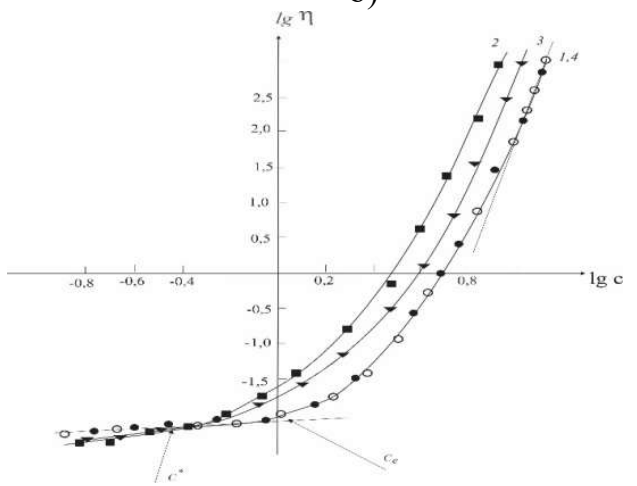

Fig. 6. The concentration dependence of the complex viscosity for solutions of CTS (a) and SCHTZ (2) in the absence (1) and presence (2-4) of drugs CFZ (2), LD (3) and DO (4) taken in an amount of $0.1 \mathrm{~mol} / \mathrm{mole}$ of CTS.

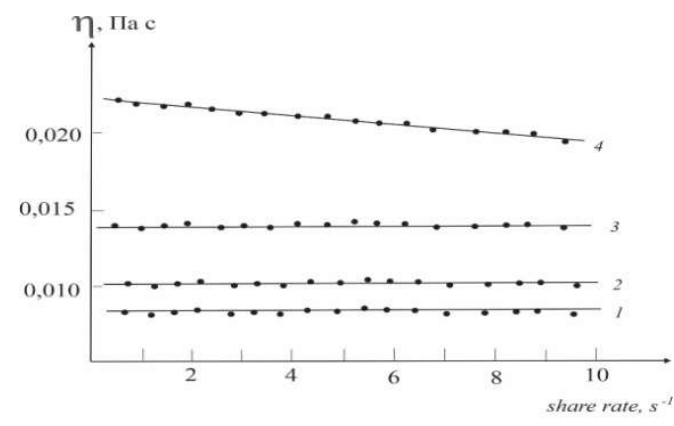

Fig. 7. The dependence of viscosity on shear rate for CTS (1.4) and SCHTZ (2.3) solutions with concentrations of $0.1(1), 0.3(2), 0.5(3)$ and $1.0(4) \mathrm{g} / \mathrm{dl}$.

a)

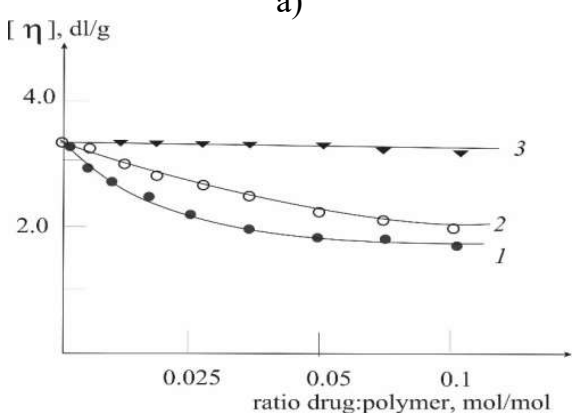

b)

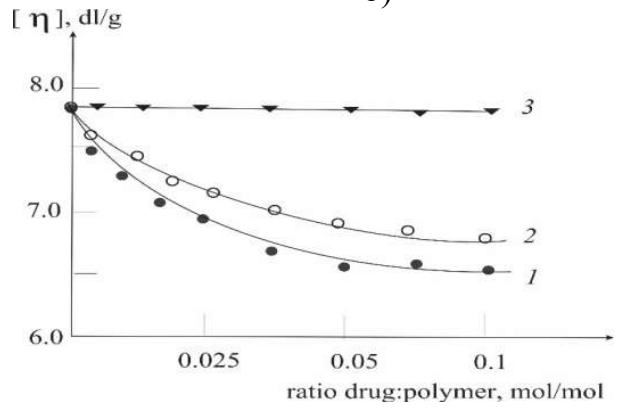

Fig. 8. The dependence of the intrinsic viscosity of SCHTZ (a) and CTS (b) on the amount of (1) CFZ, (2) LD, and (3) DO. 
The concentration of the mesh formation $C_{e}$ determined from the onset of a sharp increase in viscosity corresponds to a solution with the concentration of $1.0 \mathrm{~g} / \mathrm{dl}$ in the case of CTS and $0.8 \mathrm{~g} / \mathrm{dl}$ in the case of CTS. Taking into account the fact that the value that was counted using the Baranov's method is $[\eta]=3.20 \mathrm{dl} / \mathrm{g}$ for SCHTZ and $[\eta]=7.8 \mathrm{dl} / \mathrm{g}$ for CTS, crossover point with $C^{*}=1 /[\eta]$ for these polymers corresponds to the concentration of $0.31 \mathrm{~g} / \mathrm{dl}$ and $0.13 \mathrm{~g} / \mathrm{dl}$, respectively. As is seen from fig. 6, reaching the crossover point does not impact on the polymer flow mechanism. According to it we can say about the presence of a transition region from a diluted region to a semi-diluted region, in which macromolecules contact with each other, but still do not form the network of meshes. Obviously, in the transition zone with the increase in concentration there is a smooth compression of macromolecules coils due to their contact and overcoming the forces of electrostatic repulsion. Only after that the network of meshes starts to form in the system.

The difference in the rheological behavior of polyelectrolytes (SCHTZ and CTS) and nonpolyelectrolytes (PVA) is also evidenced by the shape of the viscosity curves (fig. 7). Curves 3 and 4 in fig. 7 characterize the solutions with the concentration above the crossover point. Nevertheless, their shape does not differ from curves 1 and 2 of the same figure, which were taken for diluted solutions. In order for solutions of ionic polymers SCHTZ and CTS to behave like pseudoplastic liquids, their concentrations should be not only greater than $C^{*}$ but reach the value of $C_{e}$. At the same time, for PVA solutions there was a clear difference in rheological behavior of polymers solutions with the concentration below and above the crossover point (compare fig. 1a and $1 \mathrm{~b}$ ).

In addition to the difference in rheological behavior of non-ionic PVA on the one hand, and ionic CTS and SCHTZ, on the other; the nature of polymers impact on the nature of the drug's effect on the conformational and supramolecular behavior of polymers. Thus, the addition of drugs (both electrolytes and nonelectrolytes) to PVA does not affect either the size of the macromolecular coil (fig. 2a), or the degree of aggregation (fig. 2b), or the viscosity of semi-diluted solutions (fig. 3). However, the addition of drugs, that are non-molecular -weight electrolytes, to the solution of ionic CTS and SCHTZ affects both the intrinsic viscosity (fig. 4) and the degree of polymer aggregation (fig. $5)$. The more drugs in solutions, the stronger the observed effect (fig. 8). It is noteworthy that for the solutions of polymers in the presence of LD and CFZ the tangent of the slope of the dependence of the specific viscosity on the concentration of the polymer in the solution in logarithmic coordinates, even in the area of large dilutions, becomes greater than 1.00. It is also can be noted that when going beyond the crossover concentration region, the values of the $\delta$ exponent are higher than for the solutions of an individual polymer or a polymer solution in the presence of DO.

Moreover, the nature of drugs (electrolyte or nonelectrolyte) plays the main role. In the case of nonelectrolyte nature of drugs (dioxidine), there are no changes in the intrinsic viscosity and the degree of aggregation.

This is confirmed by rheological studies (see fig. 6). It can be seen that the addition of DO does not affect the value of dynamic viscosity. At the same time the addition of LD and CFZ to both CTS and SCHTZ is accompanied by the decrease in the interval between $C^{*}$ and $C_{e}$ which is undoubtedly caused by the interaction between the polymer and drug-electrolyte.

All in all, in the case of using ionic polymers and drugs, which are low-molecular-weight electrolytes, their addition to solutions of polymers in a wide concentration range is accompanied by changes in the conformational and supramolecular state of polymers, and it, of course, affect the interaction of polymers with drugs, and, consequently, the ability of polymers to prolong the release of drugs.

\section{References}

1. Chen G. Q., Wu Q. The application of polyhydroxyalkanoates as tissue engineering materials // Biomaterials. 2005. No. 33. Pp. 6565-6578.

2. Park J., Ye M., Park K. Biodegradable Polymers for Microencapsulation of Drugs // Molecules. 2005. No. 1. Pp. 146-161.

3. Anurova M. N., Demina N. B., Bakhrushina E. O. Physicochemical and Technical Studies of an Interpolymer Complex of Polymethyacrylic Acid and Polyethylene Glycol as the Base for Creating Matrix Systems // Pharmaceutical Chemistry Journal. 2018. No. 7. Pp. 635-640.

4. Lowinger M. B., Barrett S. E., Zhang F., Williams R. O. Sustained release drug delivery applications of polyurethanes // Pharmaceutics. 2018. No. 2. P. 55.

5. Shtilman M. I. Biomaterials are an important area of biomedical technologies // Vestnik RGMU. 2016. No. 5. Pp. 4-15.

6. Vlakh Ye. G., Zashikhina N. N., Tennikova T. B. Perspektivnyye sistemy dostavki lekarstv na osnove amfifil'nykh polipeptidov // Aktual'nyye voprosy biologicheskoy fiziki i khimii. 2016. No. 2. Pp. 90-94.

7. Oltarzhevskaya N. D., Krichevskiy G. Ye., Korovina M. A., Gusev I. V. Biopolimery v meditsine. Uspekhi, problemy, budushcheye. Lechebnyye depo-materialy na osnove biopolimera al'ginata natriya. Printsipy sozdaniya i primeneniya (obzor) // Biofarmatsevticheskiy zhurnal. 2017. No. 2. Pp. 3-25.

8. Ipatova O. M., Torkhovskaya T. I., Medvedeva N. V., Prozorovsky V. N., Ivanova N. D., Shironin A. V., Baranova V. S., Archakov A. I. Bioavailability of oral drugs and the methods for its improvement // Biochemistry (Moscow) Supplement. Series B: Biomedical Chemistry. 2010. No. 1. Pp. 82-94.

9. Plate N. A., Vasil'yev A. Ye. Fiziologicheski aktivnyye polimery. M.: Khimiya, 1986.

10. Zhilyakova Ye. T., Popov N. N., Novikova M. Yu., Novikov O. O., Fadeyeva D. A. Izucheniye fiziko-khimicheskikh i tekhnologicheskikh kharakteristik kombinirovannogo prolongatora natriy karboksimetiltselllyulozy i polivinilovogo spirta s tsel'yu sozdaniya prolongirovannykh lekarstvennykh form s zhidkoy dispersionnoy sredoy // Nauchnyye vedomosti Belgorodskogo gosudarstvennogo universiteta. Seriya: Meditsina. Farmatsiya. 2011. No. 22-2. Pp. 69-79.

11. Novikova L. S., Shormanov V. K., Belyayeva G. V., Akhmetzyanova I. N., Belyayeva T. V. Kollagen v farmatsii i meditsine // Farmatsiya. 2011. No. 4. Pp. 52-56. 
12. Ryabtseva A. A., Rakhman Sheikh M. Kh. Some modern antihypertensive drugs for the treatment of ophthalmic hypertension and glaucoma // Clinical Ophthalmology (B-ka BC). 2001. No. 2. Pp.70-73.

13. Tentsova A. I., Alyushina M. T. Polimery v farmatsii. M.: Meditsina, 1985.

14. Litmanovich O. E., Marmuzov G. V., Eliseeva E. A., Litmanovich A. A., Papisov I. M. Effect of interaction between polyelectrolyte macromolecules and metal nanoparticles on the formation and properties of a polymer-metal nanocomposite sol // Polymer Science. Series A. 2002. Vol. 44. No. 6. Pp. 609-614.

15. Baranov V. G., Ambribakhshev D. KH., Agranova S. A., Frenkel' S. YA. Kontsentratsionnaya zavisimost' fundamental'nogo vremeni relaksatsii makromolekul // Vysokomolekulyarnyye soyedineniya. Seriya B. 1988. Vol. 30. No 5. Pp. 384.

16. Bazunova M. V., Shurshina A. S., Chernova V. V., Kulish E. I. A rheological study of molecular and supramolecular organization of chitosan succinamide in a mixed water-etanol solvent // Russian Journal of Physical Chemistry B. 2016. Vol. 10. No. 6. Pp. 1014-1021.

17. Malkin A. Ya., Isayev A. I. Reologiya: kontseptsii, metody, prilozheniya. Spb.: Professiya, 2007.
18. Schramm G. A. Practical Approach to Rheology and Rheometry. Karlsruhe, Federal Republic of Germany: Gebrueder HAAKE GmbH, 1998

19. Vinogradov G. V., Malkin A. YA. Reologiya polimerov. M.: Khimiya, 1977.

20. Ferry J. D. Viscoelastic Properties of Polymers. NewYork: Wiley, 1980.

21. Doy M., Edvards S. Dinamicheskaya teoriya polimerov. M.: Mir, 1998.

22. De Zhen P. Idei skeylinga $v$ fizike polimerov. M.: Mir, 1982.

23. Litmanovich E. A., Syaduk G. V., Lysenko E. A., Zezin A. B., Kabanov A. V., Kabanov V. A. Effect of concentration regime on rheological properties of sodium polymethacrylate and its complexes with polystyrene-poly(n-ethyl-4- vinylpyridinium bromide) block copolymer in aqueous salt solution // Polymer Science. Series A. 2006. No. 9. Pp. 997-1003.

24. Dobrynin A. V., Rubinstein M., Colby R. H. Scaling theory of polyelectrolyte solutions // Macromolecules. 1995. No. 6. Pp. 1859-1871.

25. Litmanovich E. A., Orleneva A. P., Korolev B. A., Kasaikin V. A., Kulichikhin V. G. Dynamics of polymer chain in aqueous and salt-containing aqueous solutions of poly(dimethyl diallylammonium chloride) // Polymer Science. A. 2000. No. 6. Pp. 689-693.

Received 12.10.2020 2. 